\title{
Disease progression and health care resource consumption in patients affected by hepatitis $C$ virus in real practice setting
}

This article was published in the following Dove Press journal:

ClinicoEconomics and Outcomes Research

14 October 2016

Number of times this article has been viewed

\section{Valentina Perrone \\ Diego Sangiorgi \\ Stefano Buda \\ Luca Degli Esposti}

CliCon S.r.l. Health, Economics \&

Outcomes Research, Ravenna, Italy
Correspondence: Luca Degli Esposti CliCon S.r.l., Health, Economics and Outcomes Research, Via Salara, 36 48100 Ravenna, Italy

Tel +3954438393

Fax +39544212699

Email luca.degliesposti@clicon.it
Introduction: Hepatitis $\mathrm{C}$ virus (HCV) infection represents serious health problems worldwide and is a major contributor to end-stage liver disease including cirrhosis and hepatocellular carcinoma (HCC). In Italy, $\sim 2 \%$ of subjects are infected with HCV. The objective of this study was to describe treatment patterns, disease progression, and resource use in $\mathrm{HCV}$.

Methods: An observational retrospective cohort analysis based on four Local Health Units administrative and laboratory databases was conducted. HCV-positive patients between January 1, 2009 and December 31, 2010 were included and followed-up for 1 year. To explore which covariates were associated to disease progression (cirrhosis, HCC, death for any cause), Cox proportional hazards models were performed.

Results: A total of 9,514 patients were analyzed of which $55.6 \%$ were male, aged $58.1 \pm 16.1$, and prevalence $0.4 \% ; 5.8 \%$ were positive to human immunodeficiency virus (HIV) infection, $3.0 \%$ to hepatitis B virus (HBV), and $1.6 \%$ to $\mathrm{HCV}+\mathrm{HBV}+\mathrm{HIV} ; 26.1 \%$ had cirrhosis and $4.3 \%$ HCC. The majority of patients $(76 \%)$ did not receive an antiviral treatment; the main factors affecting this decision were age, $44.1 \%$ of untreated patients being aged $>65$ years; $31 \%$ were affected by cirrhosis, $6.6 \%$ had ongoing substance or alcohol abuse, and $5.5 \%$ were affected by HCC. Disease progression in the observed timeframe was less frequent among treated patients (incidence rate per 100 patients/year: cirrhosis $2.1 \pm 0.7$ vs $13.0 \pm 1.0$, HCC $0.5 \pm 0.3$ vs $3.6 \pm 0.5$, death $0.5 \pm 0.3$ vs $6.4 \pm 0.7$ ). The annual expenditure for HCV management (drugs, hospitalizations, outpatient services) was $€ 4,700$ per patient.

Conclusion: This observational, real-life study shows that only a small proportion of patients received antiviral therapy in the territorial services investigated; among patients who were not treated, this is reflected in a disease progression and cost of management higher than treated patients. These results suggest the importance of better defining the categories of patients who can really postpone treatment, and those who require immediate antiviral therapy.

Keywords: hepatitis $\mathrm{C}$ virus, $\mathrm{HCV}$, hepatocellular carcinoma, $\mathrm{HCC}$, cirrhosis, real practice, cost of illness

\section{Introduction}

Hepatitis $\mathrm{C}$ is an infectious disease caused by the hepatitis $\mathrm{C}$ virus (HCV) and affecting primarily the liver. ${ }^{1}$ Approximately $50 \%-80 \%$ of individuals exposed to HCV develop chronic infection. ${ }^{2}$ Of these, $\sim 25 \%$ are symptomatic, but $60 \%-80 \%$ may progress to chronic liver disease, and $20 \%$ of these develop cirrhosis. ${ }^{3}$ The rate of progression to cirrhosis is highly variable and is influenced by several factors. ${ }^{4}$ Cirrhosis of the liver increases the risk of developing hepatocellular carcinoma (a form of liver cancer) $(\mathrm{HCC}) .^{3}$ 
Hepatitis C-associated liver failure is the most common indication for liver transplantation in many countries; ${ }^{5,6}$ as many as $\sim 5 \%-7 \%$ of patients may ultimately die of the consequences of the infection.

The incidence of HCV on a global scale is not well known, because acute infection is generally asymptomatic. ${ }^{7}$ It has been estimated that between 130 and 200 million people worldwide are infected with hepatitis C. ${ }^{8} \mathrm{HCV}$ prevalence is characterized by a high variability in world's regions, individual countries, and differs depending on age and risk groups within countries. ${ }^{9,10}$ A recent study, ${ }^{11}$ covering the geographical area of Europe as defined by the World Health Organization, has estimated that the prevalence of HCV varies between $2.4 \%$ for Western and Central Europe and 2.9\% for Eastern Europe.

An active surveillance program for symptomatic acute hepatitis cases in Italy reported a rate of $0.18 / 100,000$ inhabitants in $2010 .^{12}$ However, the epidemiology of HCV infection has undergone substantial changes over the past two decades, with a progressive decrease in incidence and a shift in risk factors. ${ }^{12}$ About $15 \%-45 \%$ of infected persons spontaneously clear the virus within 6 months of infection without any treatment. ${ }^{8}$ The remaining $55 \%-85 \%$ of persons will develop chronic $\mathrm{HCV}$ infection. Of those with chronic $\mathrm{HCV}$ infection, the risk of cirrhosis of the liver is $15 \%-30 \%$ within 20 years. ${ }^{8}$ However, no more than $20 \%$ of patients with advanced liver disease receive treatment. ${ }^{13,14}$

The standard treatment is a combination of pegylated interferon alpha (PegIFN) and ribavirin for a period of 24 or 48 weeks, depending on HCV genotype. ${ }^{15}$ The primary goal of $\mathrm{HCV}$ therapy is to cure the infection and prevent the complications of chronic liver disease and extrahepatic diseases, including liver necroinflammation, fibrosis, cirrhosis, $\mathrm{HCC}$, and death.

The economic burden of HCV-induced pathologies is significant both to the individual and to society. The health resources utilization tends to increase with disease severity. In addition to the direct costs to be incurred for disease management, there are indirect costs linked to the loss of productivity due to disability and premature death in patients suffering from the HCV chronic infections. ${ }^{16}$

The aim of this study was to describe treatment patterns and resource use among patients affected by HCV and to describe prevalence and disease progression of patients affected by $\mathrm{HCV}$ in relation to treatment.

\section{Methods}

\section{Data sources}

The study was conducted using administrative databases of four Italian Local Health Units (LHUs) ( 2.5 million healthassisted individuals).
Using the Health-assisted Subject Databases that contain patients' demographic data (year of birth and sex), date of death (if any), clinical information on presence of comorbidities; Medication Prescription Databases that provides information for each medication prescription, such as the prescribing physician's number, the anatomical-therapeutic-chemical (ATC) code of the drug purchased, the number of packs, the number of units per pack, the dosages, the unit cost per pack, and the prescription date; Hospital Discharge Database that contains information on discharge for each hospitalization, in particular the date of admission and discharge, main and accessory diagnosis, coded according to the International Classification of Diseases, Ninth Revision, Clinical Modification (ICD-9 CM) and Diagnosis-Related Group (DRG) reimbursement rate; the Laboratory Analysis Database that records the date and result of the viral load, antibodies and genotype tests provided to the patient; two out of four LHUs provided all data related to patients who performed a HCV test; therefore, those two LHUs were used to calculate $\mathrm{HCV}$ prevalence. To guarantee patient privacy, each subject was assigned an anonymous univocal numeric code. No identifiers related to patients were provided to the researchers. The patient code in each database permitted electronic linkage between all databases. Informed consent is not required for using encrypted retrospective information. This study was notified to the local ethics committee in each participating LHU according to the Italian law regarding the conduct of observational analysis and the LHU Ethics Committees approved the study. ${ }^{17}$

\section{Cohort definition}

This was a retrospective cohort study, which included all HCVpositive patients aged $\geq 18$ years if, between January 1, 2009 and December 31, 2010, they had at least one prescription of PegIFN alfa-2b or PegIFN alfa-2a (ATC codes: L03AB10, L03AB11, L03AB60, L03AB61) plus ribavirin (ATC code: J05AB04), and/or hospitalization for HCV (ICD-9 CM codes: 070.4X, 070.5X, 070.7X), and/or laboratory tests (HCV RNA, antibodies, immunoblotting, genotype assignment), and/or patients with previous resource consumption for HCV. The index date was identified according to the first benefit for $\mathrm{HCV}$ during the enrolment period. Patients were followed-up for 1 year from the index date and clinical characteristics of the patients enrolled in this study were investigated for 1 year period before the index date. Patients transferred during the observational period were excluded.

The cirrhosis and $\mathrm{HCC}$ were identified as the presence of hospitalizations cirrhosis or HCC related [(ICD-9 CM code: 571.XX) and (ICD-9 CM code: 155.XX), respectively] at baseline. The coinfection with human Human Immunodeficiency 
Virus (HIV) was identified as the presence of DRG codes: 488, 489, 490, or hospitalization HIV related (ICD-9 CM code: 042.XX), or use of combined antiretroviral agents (ATC code: J05A). Finally, Hepatitis B virus (HBV) was identified as the presence of hospitalization $\mathrm{HBV}$ related (ICD-9 CM codes: $070.2 \mathrm{X}, 070.3 \mathrm{X}$ ), or use of lamivudine (ATC code: J05AF05), adefovir dipivoxil (ATC code: J05AF08), entecavir (ATC code:J05AF10), Telbivudine (ATC code: J05AF11).

\section{Cost analysis}

Costs are reported in euros $(€)$. The consumption of health care resources was evaluated in the 12 months after index date (follow-up period). The costs for hospitalizations, treatment patterns, and outpatient specialist services were classified as related and not related to the disease analysis. Drug costs were evaluated using the National Health Service purchase price, while the costs for the hospitalizations were derived from the DRG tariff codes and the cost of instrumental and laboratory tests was defined according to the tariffs applied by the Toscana, Emilia Romagna, Campania, and Lombardy regions.

\section{Statistical analysis}

Continuous variables were reported as mean and standard deviation (median and range as appropriate) and compared using $t$-test (Mann-Whitney test as appropriate), whereas categorical variables were expressed as numbers and percentages and compared using chi-square test. Incidence rates per 100 patient/years were used to describe risk of progression. For the evaluation of incidence rates of cirrhosis and HCC, all patients with baseline cirrhosis and HCC were excluded. We identified presence of cirrhosis or HCC through ICD-9 CM code: 571.XX and 155.XX at the baseline. As an extension to this analysis and to explore which covariates were associated to risk of disease progression during the follow-up period, four Cox proportional hazards multivariable regression models were performed, considering, as outcomes, cirrhosis, $\mathrm{HCC}$, death for any cause. Covariates include sex, age, previous treatments, coinfection with HIV/HBV, anemia, ongoing substance or alcohol abuse. Schoenfeld residual analysis was used to validate the proportional hazards assumption. Two-tailed $P$-values $<0.05$ were considered significant. All analyses were performed using STATA software version 12.0 (Stata Corporation, College Station, TX, USA).

\section{Results}

A total of 9,514 patients were analyzed, 55.6\% were male, aged $58.1 \pm 16.1$ years. Prevalence was estimated to be $0.4 \%$. According to the results, the age ranges with the highest percentage of $\mathrm{HCV}$ patients are as follows: $25.7 \%$ were females aged 60-69 years, while $23.7 \%$ were maled aged 40-49 years. Patients affected by HIV and HBV were 5.8\% and 3.0\%, respectively; of these, $1.6 \%$ were coinfected with $\mathrm{HCV}, \mathrm{HBV}$, and HIV. Patients affected by depression and anemia were $20.9 \%$ and $16.8 \%$, respectively, and $26.1 \%$ had compensated or decompensated cirrhosis, while $4.3 \%$ had HCC (Table 1). The majority of patients (76\%) affected by HCV infection had received no antiviral treatment; the main reasons of this were age, $44.1 \%$ of untreated patients being aged $>65$ years; of them, $31 \%$ were affected by cirrhosis, $6.6 \%$ had ongoing substance or alcohol abuse, and $5.5 \%$ were affected by HCC (Table 2).

Disease progression was slower in treated patients, with the following incidence rate per 100 patients/year: cirrhosis $2.1 \pm 0.7$ versus $13.0 \pm 1.0(P<0.001)$, HCC $0.5 \pm 0.3$ versus $3.6 \pm 0.5(P<0.001)$, death for any cause $0.5 \pm 0.3$ versus $6.4 \pm 0.7(P<0.001)$ (Figure 1); at multivariable Cox regression models, hazard ratios were, respectively, 0.30 (95\% CI: 0.21-0.43, $P=0.000), 0.41$ (95\% CI: 0.19-0.92, $P=0.030$ ), and 0.24 (95\% CI: 0.12-0.48, $P=0.000)$ (Table 3).

Considering only patients who were not affected by cirrhosis or $\mathrm{HCC}$, the percentage of treated patients was low,

Table I Demographic characteristics

\begin{tabular}{ll}
\hline Characteristics & Number of subjects (\%) \\
\hline Beneficiaries & $2,546,000$ \\
HCV-positive & $9,514(0.4 \%$ among total beneficiaries) \\
Male & $5,289(55.6)$ \\
Age (years), mean \pm SD & $58.1 \pm 16.1$ \\
HIV & $554(5.8)$ \\
HBV & $284(3.0)$ \\
HCV/HIV-coinfected & $149(1.6)$ \\
Depression & $1,988(20.9)$ \\
Anemia & $1,615(16.8)$ \\
Cirrhosis & $2,487(26.1)$ \\
HCC & $409(4.3)$ \\
\hline
\end{tabular}

Abbreviations: $\mathrm{HBV}$, hepatitis $B$ virus; $\mathrm{HCC}$, hepatocellular carcinoma; $\mathrm{HCV}$, hepatitis $C$ virus; HIV, human immunodeficiency virus; SD, standard deviation.

Table 2 The main characteristic among treated and untreated patients affected by hepatitis $C$ virus

\begin{tabular}{llll}
\hline & $\begin{array}{l}\text { Untreated*, } \\
\mathbf{n ~ ( \% )}\end{array}$ & $\begin{array}{l}\text { Treated, } \\
\mathbf{n ~ ( \% )}\end{array}$ & P-value \\
\hline Patients & $7,24 I(76)$ & $2,273(24.0)$ & \\
Age (years), mean \pm SD & $60.4 \pm 16.2$ & $50.6 \pm 12.9$ & 0.000 \\
$\quad>65$ & $3,195(44.1)$ & $308(13.6)$ & 0.000 \\
$>70$ & $2,275(31.4)$ & $101(4.4)$ & 0.000 \\
Male & $3,919(54.1)$ & $1,370(60.3)$ & 0.000 \\
Substance or alcohol abuse & $476(6.6)$ & $94(4.1)$ & 0.000 \\
Cirrhosis & $2,239(31.0)$ & $248(11.0)$ & \\
Hepatocellular carcinoma & $395(5.5)$ & $14(0.6)$ & \\
\hline
\end{tabular}

Notes: *Characterization or follow-up period. 


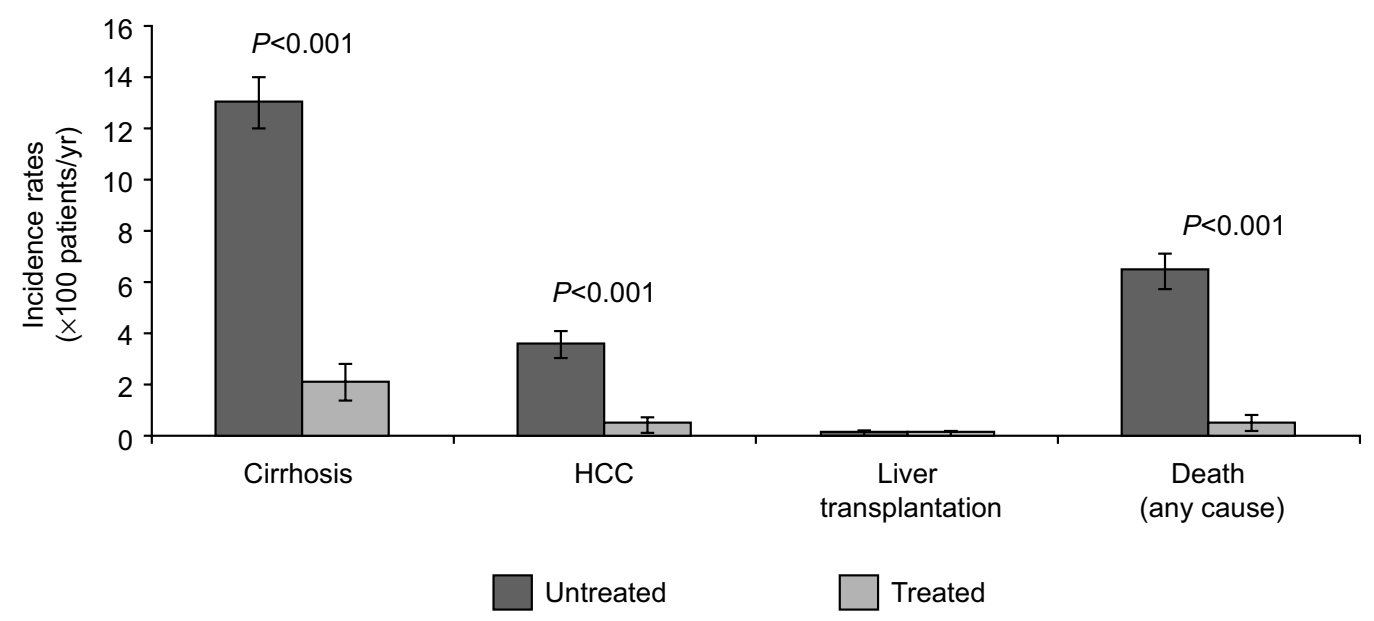

Figure I Disease progression (incidence) among treated and untreated patients affected by hepatitis $C$ virus. Note: Patients with previous hospitalizations for cirrhosis or hepatocellular carcinoma were excluded.

Abbreviation: HCC, hepatocellular carcinoma.

Table 3 Cox proportional hazards regression model

\begin{tabular}{|c|c|c|c|c|c|c|c|c|c|}
\hline & \multicolumn{3}{|c|}{ Cirrhosis } & \multicolumn{3}{|l|}{ HCC } & \multicolumn{3}{|c|}{ Death (any cause) } \\
\hline & HR & $95 \% \mathrm{Cl}$ & $P$-value & HR & $95 \% \mathrm{Cl}$ & $P$-value & HR & $95 \% \mathrm{Cl}$ & $P$-value \\
\hline Male & 1.384 & $1.140-1.679$ & 0.001 & 3.113 & $1.924-5.037$ & 0.000 & 1.089 & $0.875-1.356$ & 0.443 \\
\hline Age $>65$ years & 1.946 & $1.58 \mathrm{I}-2.394$ & 0.000 & 6.282 & $3.658-10.786$ & 0.000 & 7.563 & $5.285-10.824$ & 0.000 \\
\hline Established* & 0.262 & $0.108-0.635$ & 0.003 & 0.274 & $0.038-1.988$ & 0.200 & & & \\
\hline Treated & 0.300 & $0.207-0.434$ & 0.000 & 0.414 & $0.186-0.920$ & 0.030 & 0.243 & $0.125-0.475$ & 0.000 \\
\hline HIV & 0.872 & $0.668-1.138$ & 0.314 & 1.958 & $1.274-3.009$ & 0.002 & 1.971 & $|.437-2.70|$ & 0.000 \\
\hline HBV & 1.620 & $1.075-2.442$ & 0.021 & 1.470 & $0.725-2.982$ & 0.285 & 0.903 & $0.542-1.502$ & 0.693 \\
\hline Anemia & 1.583 & $1.334-1.880$ & 0.000 & 0.982 & $0.623-1.549$ & 0.938 & 2.123 & $1.811-2.490$ & 0.000 \\
\hline Substance or alcohol abuse & 1.077 & $0.804-1.444$ & 0.618 & 0.852 & $0.367-1.98 \mid$ & 0.710 & 1.370 & $0.94 I-I .994$ & 0.100 \\
\hline Number of $\mathrm{HCV}$ tests & 0.910 & $0.85 \mathrm{I}-0.972$ & 0.005 & 0.976 & $0.852-1.119$ & 0.731 & 0.540 & $0.457-0.638$ & 0.000 \\
\hline Number of ALT tests & 1.077 & $1.047-1.107$ & 0.000 & 1.074 & $1.011-1.141$ & 0.021 & 0.906 & $0.853-0.962$ & 0.001 \\
\hline
\end{tabular}

Note: Patients with previous hospitalizations for cirrhosis or $\mathrm{HCC}$ were excluded. *Patients were already in treatment with anti $\mathrm{HCV}$ agents before the observational study period.

Abbreviations: ALT, alanine aminotransferase; Cl, confidence interval; HBV, hepatitis B virus; HCC, hepatocellular carcinoma; HCV, hepatitis C virus; HIV, human immunodeficiency virus; HR, hazard ratio.

being equal to $25 \%$ (Figure 2). The rate of hospitalization for $\mathrm{HCV}$ was higher in untreated $(46.9 \%)$ versus treated $(23.6 \%)$ patients; this percentage was similar in a cohort of patients affected by cirrhosis or HCC (untreated $44.6 \%$ vs treated $22.7 \%$ ).

The overall annual expenditure for the management of HCV was $€ 4,673.50$ per patient, of which $€ 2,839(60.7 \%)$ was for hospitalizations and $€ 1,673.8$ (35.8\%) for drug treatment; this amount varied considerably among the different subgroups in analysis; in particular, treated patients showed a nonpharmacological expenditure (hospitalizations, outpatient services) of $€ 997$ (14\% of total cost), compared to untreated patients $(€ 3,532,88 \%$ of total cost $)(P<0.001)$ (Table 4); coinfected (with HBV, HIV, or both) patients showed a nonpharmacological expenditure of $€ 4,410$ (45\%), while patients without coinfections showed expenditure of $€ 2,890(68 \%)(P<0.001)$ (Table 5).

\section{Discussion}

In the past few years, care for hepatitis $C$ has evolved rapidly with increasingly effective and better-tolerated antiviral therapies being evaluated and approved for use. ${ }^{15,18}$ Our study provides a 'real-life' snapshot of how this disease is being addressed in the pre-Direct Acting Antiviral era and in a cohort of $>2$ million beneficiaries.

The epidemiology of hepatitis $\mathrm{C}$ in Italy has changed in recent decades, with a progressive decrease in incidence. ${ }^{19}$ In Italy, the proportion of subjects infected with $\mathrm{HCV}$ is $\sim 2 \%$ of the general population with a gradient that increases from the north to the south to the Islands of Sardinia and Sicily, and with age $\left(60 \%\right.$ of patients with hepatitis $\mathrm{C}$ are $>65$ years). ${ }^{19}$ However, epidemiological studies were performed on a limited number of patients, who are not representative of the global Italian population. ${ }^{20}$ Our data demonstrates that among beneficiaries, the prevalence of confirmed $\mathrm{HCV}$ 

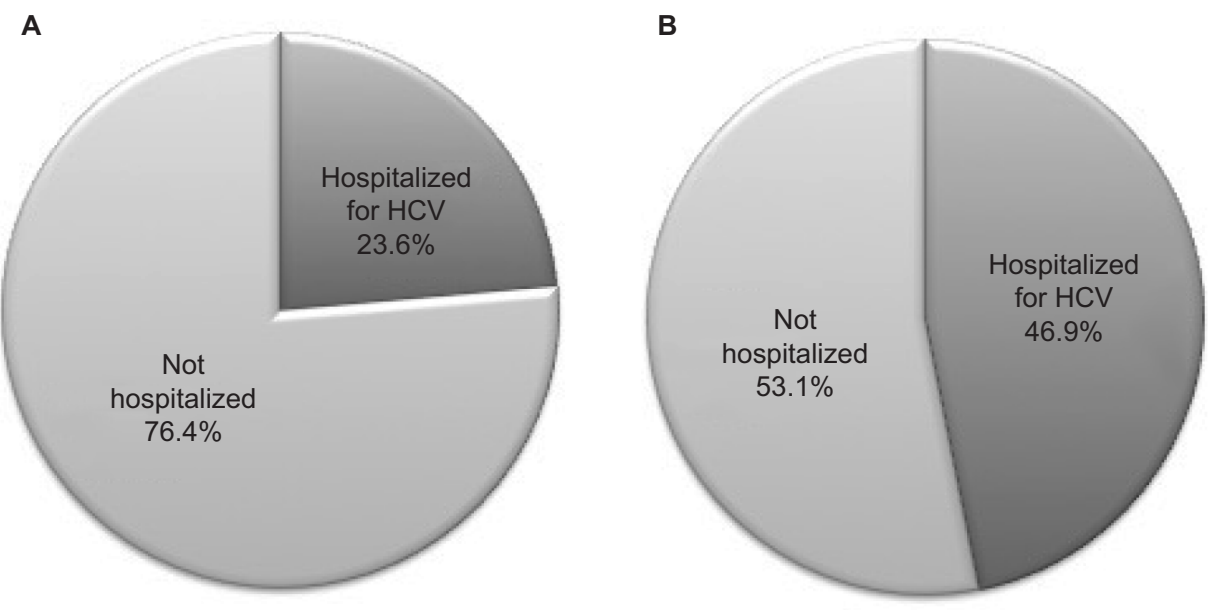

Figure 2 Resource consumption among treated (A) and untreated (B) HCV patients who were not affected by cirrhosis or HCC.

Note: A. Treated patients ( $n=1,746,25.1 \%$ of all HCV-positive patients who were not affected by cirrhosis or HCC) B. Untreated patients ( $n=5,210,74.9 \%$ of all HCVpositive patients who were not affected by cirrhosis or HCC).

Abbreviations: $\mathrm{HCC}$, hepatocellular carcinoma; $\mathrm{HCV}$, hepatitis $\mathrm{C}$ virus.

Table 4 Cost of illness among treated and untreated patients affected by hepatitis $C$ virus

\begin{tabular}{|c|c|c|c|c|c|c|c|c|c|}
\hline & \multicolumn{3}{|l|}{ Total } & \multicolumn{3}{|c|}{ Untreated } & \multicolumn{3}{|l|}{ Treated } \\
\hline & Mean $(€)$ & $\%$ & SD & Mean $(€)$ & $\%$ & SD & Mean $(€)$ & $\%$ & SD \\
\hline \multicolumn{10}{|l|}{ Cost of HCV-related } \\
\hline Drugs & $1,187.10$ & 25.4 & $3,129.90$ & 0.00 & 0.0 & 0.00 & $5,658.60$ & 79.3 & $4,625.70$ \\
\hline Other ATC code J & 317.2 & 6.8 & $\mathrm{I}, 654.50$ & 323.30 & 8.0 & I,672.30 & 294.40 & 4.1 & $\mathrm{I}, 585.70$ \\
\hline Other ATC code L & 169.5 & 3.6 & $1,454.90$ & 164.00 & 4.1 & $1,363.60$ & 190.00 & 2.7 & $\mathrm{I}, 757.00$ \\
\hline Hospitalization & $2,839.00$ & 60.7 & $7,499.50$ & $3,408.00$ & 84.8 & $8,182.30$ & 696.20 & 9.8 & $3,179.80$ \\
\hline Outpatient services & 160.70 & 3.4 & 214.80 & 123.50 & 3.1 & 169.70 & 300.70 & 4.2 & 294.20 \\
\hline Cost not HCV-related & $3,121.10$ & 40.0 & & & & & & & \\
\hline Total & $4,673.50$ & 60.0 & & $4,0 \mid 8.80$ & & & $7,139.90$ & & \\
\hline
\end{tabular}

Note: ATC code J Antiinfectives for systemic use; ATC code L Antineoplastic and immunomodulating agents.

Abbreviations: ATC, anatomical-therapeutic-chemical; SD, standard deviation.

Table 5 Cost of illness in patients affected by hepatitis $C$ virus, with and without coinfections

\begin{tabular}{|c|c|c|c|c|c|c|}
\hline & \multicolumn{3}{|c|}{$\begin{array}{l}\text { Coinfections } \\
\text { (HBV and/or HIV) }\end{array}$} & \multicolumn{3}{|c|}{ No coinfections } \\
\hline & Mean (€) & $\%$ & SD & Mean (€) & $\%$ & SD \\
\hline \multicolumn{7}{|l|}{$\begin{array}{l}\text { Cost of HCV- } \\
\text { related }\end{array}$} \\
\hline Drugs & $1,069.80$ & 11 & $3,214.00$ & $1,196.30$ & 28 & $3,123.20$ \\
\hline $\begin{array}{l}\text { Other ATC } \\
\text { code J }\end{array}$ & $3,874.70$ & 39.8 & $4,860.10$ & 39.30 & 0.9 & 219.60 \\
\hline $\begin{array}{l}\text { Other ATC } \\
\text { code L }\end{array}$ & 376.30 & 3.9 & $\mathrm{I}, 774.90$ & 153.30 & 3.6 & $\mathrm{I}, 425.80$ \\
\hline Hospitalization & $4,255.20$ & 43.7 & $11,522.80$ & $2,728.60$ & 63.8 & $7,079.70$ \\
\hline $\begin{array}{l}\text { Outpatient } \\
\text { services }\end{array}$ & 154.60 & 1.6 & 178.80 & 161.10 & 3.8 & 217.30 \\
\hline Total & $9,730.60$ & & & $4,279.20$ & & \\
\hline
\end{tabular}

Note: ATC code J Antiinfectives for systemic use; ATC code L Antineoplastic and immunomodulating agents.

Abbreviations: ATC, anatomical-therapeutic-chemical; HBV, hepatitis B virus; HIV, human immunodeficiency virus; SD, standard deviation. positivity was $0.4 \%$. Although this is likely to be underestimated because it is well known that HCV infection is rarely symptomatic during its acute phase. , $^{4,21}$

Liver problems are among the most common complications of hepatitis $\mathrm{C}$ infection, in agreement with current evidence, ${ }^{22}$ liver cirrhosis was the most frequent complication in the patients we studied. There is strong evidence demonstrating the association of chronic HCV infection to cirrhosis usually requiring the passage of two or more decades, and occurring more often in persons infected at older ages (particularly male), or obese or with substantial hepatic steatosis or with HIV coinfection; ${ }^{23}$ among investigated cofactors determining the natural history of the infection, alcohol is undoubtedly a factor most related to the risk of progression to cirrhosis. ${ }^{24}$

This study indicates that only a small proportion of individuals with confirmed $\mathrm{HCV}$ infection have received antiviral treatment; those results were confirmed also for 
patients without cirrhosis and HCC. Despite the long-term morbidity associated with hepatitis $\mathrm{C}$ and the availability of effective treatments, less than a quarter of infected individuals were treated with an antiviral therapy. A large multicenter prospective Italian study showed that only $33 \%$ of evaluated HCV-positive subjects were treated with current standard of antiviral therapy. ${ }^{25}$

We found that this lack of treatment was the consequence of underdiagnosis and reflects a lack of awareness on the part of patients, barriers to accessing treatment, and the complexity and tolerability of current treatments. ${ }^{26}$ At the same time and in accordance with previous reports ${ }^{27-30}$ the most frequent reasons for the lack of treatment were advanced age, alcohol abuse, and active staging of disease. We also noted that among patients who did not receive the treatment, the rate of progression of disease was higher than in patients who underwent therapy. In particular, we observed that patients receiving no treatment led to an increase in health care resources, especially in terms of hospitalizations. This can be explained, at least in part, by the fact that the treatment of hepatitis $\mathrm{C}$ has the potential to slow or halt liver disease progression and reduce the risk of long-term consequences including liver cancer and liver-related death.

Our results are in agreement with previous analyses that showed that HCV treatment was associated with significant reductions in subsequent all-cause direct health care cost in the follow-up period and that health care costs increased in a stepwise fashion as HCV-related liver disease progressed. ${ }^{31,32}$ Indeed, an analysis of data from a cohort of 33,309 patients with chronic HCV infection showed that treated patients ( $12 \%$ of total patients) were associated with lower health care costs, and these savings were independent of baseline patient comorbidities and stage of disease. ${ }^{33}$

These analyses suggest that an appropriate therapeutic strategy could lead to reduced expenditures for hospitalizations; in the overall HCV population, we observed that hospitalizations represent two-thirds of the cost of illness, while one-third of the expenditure is driven by the pharmacological treatment; among treated patients, hospitalizations represent one-seventh of the cost of illness; cost for hospitalization for untreated patients was almost fourfold as compared to treated patients. However, our results showed that older patients and patients with cirrhosis were less often treated. This could influence the fact that treated patients had lower hospitalization costs as we expect more hospitalization for older and sick patients.

Our retrospective study has certain limitations intrinsic to it being of observational nature and on administrative databases. The information on previous treatments and tests were collected from outpatient records, and some data may therefore have been missed due to incomplete or lost medical records; hence a possible underestimation of the $\mathrm{HCV}$ prevalence and coinfection and/or comorbidity status. The important clinical information, such as severity of disease, clinical response to treatment, and the reason of no treatment, is not captured.

In conclusion, in the real-life setting, a large proportion of $\mathrm{HCV}$-positive patients did not receive treatment, for a number of different reasons. This correlates with a progression of disease and a higher cost of management in untreated versus treated patients. These results suggest the importance of better defining the categories of patients who can really postpone treatment, and those who, by contrast, require immediate antiviral therapy.

\section{Author contributions}

All authors contributed toward data analysis, drafting, and revising the paper, gave final approval of the version to be published, and agree to be accountable for all aspects of the work.

\section{Disclosure}

The authors report no conflicts of interest in this work.

\section{References}

1. Lauer GM, Walker BD. Hepatitis C virus infection. $N$ Engl J Med. 2001;345(1):41-52.

2. Seeff LB. The history of the "natural history" of hepatitis C (19682009). Liver Int. 2009;29(Suppl 1):89-99.

3. World Health Organization (WHO). 2002 Hepatitis C. Available from: http://www.who.int/csr/disease/hepatitis/whocdscsrlyo2003/en/. Accessed November 18, 2014.

4. Chen SL, Morgan TR. The natural history of hepatitis C virus (HCV) infection. Int J Med Sci. 2006;3(2):47-52.

5. Wasley A, Alter MJ. Epidemiology of hepatitis C: geographic differences and temporal trends. Semin Liver Dis. 2000;20(1):1-16.

6. Charlton M. Hepatitis C infection in liver transplantation. Am J Transplant. 2001;1(3):197-203.

7. Lavanchy D. Evolving epidemiology of hepatitis $\mathrm{C}$ virus. Clin Microbiol Infect. 2011;17(2):107-115.

8. World Health Organization. Guidelines for the Screening, Care and Treatment of Persons with Hepatitis C Infection; 2014. Available from: http://www.who.int/hiv/pub/hepatitis/hepatitis-c-guidelines/en/. Accessed June 28, 2016.

9. Strazzulla A, Costa C, Pisani V, et al. Present, old and future strategies for anti-HCV treatment in patients infected by genotype-1: estimation of the drug costs in the Calabria Region in the era of the directly acting antivirals. BMC Infect Dis. 2014;14 (Suppl 5):S3.

10. Negro F. Epidemiology of hepatitis C in Europe. Dig Liver Dis. 2014;46(Supp1 5):S158-S164.

11. Mohd Hanafiah K, Groeger J, Flaxman AD, Wiersma ST. Global epidemiology of hepatitis $\mathrm{C}$ virus infection: new estimates of age-specific antibody to HCV seroprevalence. Hepatology. 2013;57(4):1333-1342.

12. SEIEVA Collaborative Group: Epidemiology of acute viral hepatitis in Italy: results of the surveillance through SEIEVA. Annual Report Rome; 2015. Available from: http://www.iss.it/seieva/index. php?lang=1\&anno=2016\&tipo=5. Accessed August 24, 2016. 
13. Deuffic-Burban S, Castel H, Wiegand J, Manns MP, Wedemeyer H, Mathurin P, Yazdanpanah Y. Immediate vs. delayed treatment in patients with acute hepatitis C based on IL28B polymorphism: a model-based analysis. J Hepatol. 2012;57(2):260-266.

14. Holmberg SD, Spradling PR, Moorman AC, Denniston MM. Hepatitis C in the United States. N Engl J Med. 2013;368(20):1859-1861.

15. European Association for the Study of the Liver. EASL recommendations on treatment of hepatitis C 2014. J Hepatol. 2014;61(2):373-395.

16. Mennini FS, Marcellusi A, Andreoni M, Gasbarrini A, Salomone S, Craxi A. Health policy model: long-term predictive results associated with the management of hepatitis $\mathrm{C}$ virus-induced diseases in Italy. Clinicoecon Outcomes Res. 2014;6:303-310.

17. AIFA Guideline for the Classification and Conduction of the Observational Studies on Medicines. Available from: https://www agenziafarmaco.gov.it/ricclin/sites/default/files/files_wysiwyg/files/ CIRCULARS/Circular\%2031st\%20May\%202010.pdf. Accessed June 28, 2016.

18. Manns MP, von Hahn T. Novel therapies for hepatitis $\mathrm{C}-$ one pill fits all? Nat Rev Drug Discov. 2013;12(8):595-610.

19. Epidemiologia, sorveglianza e promozionde della salute (SEIEVA). Istituto Superiore di Sanità (ISS) [National Center for Epidemiology, Surveillance and Health Promotion. SEIEVA Collaborative Group (Italian Nationa Institute of Health)]. Available from: http:/www.iss.it/seieva/index php?lang=1\&anno=2014\&tipo=4. Last update: November 28, 2014.

20. Marascio N, Liberto M, Barreca G, et al. Update on epidemiology of HCV in Italy: focus on the Calabria Region. BMC Infect Dis. 2014;14(Supp1 5):S2.

21. Marcellin P. Hepatitis C: the clinical spectrum of the disease. J Hepatol. 1999;31(Suppl 1):9-16.

22. Chopra S, Di Bisceglie AM, Bloom A. UpToDate. Hepatitis C; 2016 Available from: http://www.uptodate.com/contents/hepatitis-c-beyondthe-basics. Accessed June 28, 2016.

23. Ascione A, Tartaglione T, Di Costanzo GG. Natural history of chronic hepatitis C virus infection. Dig Liver Dis. 2007;39(Suppl 1):S4-S7.
24. Corrao G, Arico S. Independent and combined action of hepatitis C virus infection and alcohol consumption on the risk of symptomatic liver cirrhosis. Hepatology. 1998;27(4):914-919.

25. Stroffolini T, Spadaro A, Guadagnino V, et al. Current practice of hepatitis C treatment in Southern Italy. Dig Liver Dis. 2010;42(11):822-825.

26. McGowan CE, Monis A, Bacon BR, et al. A global view of hepatitis $\mathrm{C}$ : physician knowledge, opinions, and perceived barriers to care. Hepatology. 2013;57(4):1325-1332.

27. Pereira K, Miranda AC, Baptista T, et al. Analysis of hepatitis nontreatment causes in a cohort of $\mathrm{HCV}$ and $\mathrm{HCV} / \mathrm{HIV}$ infected patients. J Int AIDS Soc. 2014;17(4 Suppl 3):19645.

28. Morrill JA, Shrestha M, Grant RW. Barriers to the treatment of hepatitis C. Patient, provider, and system factors. J Gen Intern Med. 2005;20(8):754-758.

29. Crespo J, Cabezas J, Sacristan B, et al. Barriers to HCV treatment in the era of triple therapy: a prospective multi-centred study in clinical practice. Liver Int. 2015;35(2):401-408.

30. Bini EJ, Brau N, Currie S, et al. Prospective multicenter study of eligibility for antiviral therapy among 4,084 U.S. veterans with chronic hepatitis C virus infection. Am J Gastroenterol. 2005;100(8):1772-1779.

31. McAdam-Marx C, McGarry LJ, Hane CA, Biskupiak J, Deniz B, Brixner DI. All-cause and incremental per patient per year cost associated with chronic hepatitis $\mathrm{C}$ virus and associated liver complications in the United States: a managed care perspective. J Manag Care Pharm. 2011;17(7):531-546.

32. Gordon SC, Pockros PJ, Terrault NA, Hoop RS, Buikema A, Nerenz $\mathrm{D}$, Hamzeh FM. Impact of disease severity on healthcare costs in patients with chronic hepatitis $\mathrm{C}$ (CHC) virus infection. Hepatology. 2012;56(5):1651-1660.

33. Gordon SC, Hamzeh FM, Pockros PJ, Hoop RS, Buikema AR, Korner EJ, Terrault NA. Hepatitis C virus therapy is associated with lower health care costs not only in noncirrhotic patients but also in patients with end-stage liver disease. Aliment Pharmacol Ther. 2013;38(7): 784-793.
ClinicoEconomics and Outcomes Research

\section{Publish your work in this journal}

ClinicoEconomics and Outcomes Research is an international, peerreviewed open-access journal focusing on health technology assessment, pharmacoeconomics and outcomes research in the areas of diagnosis, medical devices, and clinical, surgical and pharmacological intervention. The economic impact of health policy and health systems
Submit your manuscript here: https://www.dovepress.com/clinicoeconomics-and-outcomes-reserch-jounas

organization also constitute important areas of coverage. The manuscript management system is completely online and includes a very quick and fair peer-review system, which is all easy to use. Visit http://www.dovepress.com/testimonials.php to read real quotes from published authors. 